CARDIOVASCULAR MEDICINE

\title{
Simplified cardioversion service with intravenous midazolam
}

\author{
P J B Hubner, S Gupta, I McClellan
}

Heart 2004;90:1447-1449. doi: 10.1136/hrt.2003.033050

See end of article for authors' affiliations ....................

Correspondence to: Dr Suzane Gupta; suzane. gupta@uhl-tr.nhs.uk

Accepted 15 July 2004
Objective: To assess the results of a new cardioversion service that used intravenous midazolam sedation with cardioversion performed with a biphasic defibrillator by an experienced doctor with a prior review of patients in a pre-cardioversion clinic.

Methods: 368 consecutive patients who were treated under the new service over its first 12 months (group 1) were compared with 210 consecutive patients who attended under the old system during the preceding 12 months (group 2). Patients of group 2 had cardioversion under general anaesthesia by junior doctors with a monophasic defibrillator.

Results: There were no anaesthetic or respiratory complications in group 1. Of the patients in group 1, $10.3 \%$ remembered the shocks, with only $3.5 \%$ considering them unpleasant. Cardioversion was successful in $94.6 \%$ of group 1 patients after a mean energy of $117 \mathrm{~J}$ compared with $81.4 \%$ ( $p<0.0001$ ) and a mean energy of $242 \mathrm{~J}(\mathrm{p}<0.0001)$ for group 2 patients. Cancellations on the day of the procedure were reduced from $24 \%$ in group 2 to $3.4 \%$ in group 1 .

Conclusions: The new service was found to be safe and more efficient. It has led to a large reduction in the waiting time for cardioversion.
$F$ ollowing reports of intravenous midazolam and diazepam sedation for cardioversion, ${ }^{12}$ we believed that this would simplify the procedure, as an anaesthetist would no longer routinely be needed. ${ }^{3}$ We reviewed the whole cardioversion process, and changed the defibrillator to a biphasic one, which uses about half the current strength of a monophasic machine. ${ }^{45}$ Cardioversions were performed on a session basis by a more senior doctor (medical assistant) experienced in airway management. ${ }^{6}$ All patients were seen two days before cardioversion in a nurse run pre-cardioversion clinic to ensure that international normalised ratios (INRs) had been satisfactory for at least four weeks and that an echocardiogram had been recorded and tests such as for thyroid function had been completed. An ECG was checked, the procedure was explained to the patient and their consent was obtained.

We report a prospective audit of the new service over 12 months and compare the results with those of the preceding year under the old system.

\section{METHODS}

\section{Cardioversion process}

Cardioversion was performed during a morning session on the cardiology day care ward. Patients were admitted at 8 am after fasting from midnight.

A nurse inserted an intravenous cannula. With patients lying on their backs on a trolley, leads from a Zoll M Series biphasic defibrillator (Zoll Medical UK Ltd, Cheshire, UK) were attached together with a finger oximeter. Oxygen was administered through a facemask. For the first six months an anaesthetist was present but after this time one was available only on call.

After midazolam $2.5 \mathrm{mg}$ was given intravenously, there was a two minute wait before a further $1 \mathrm{mg}$ midazolam bolus was given and repeated at 1-2 minute intervals. The patient was considered adequately sedated when he or she appeared sleepy with the eyelids closed or half closed and no longer continued a conversation. There was no response to soft verbal commands and mild tactile stimuli. When the gel pads, which were relatively cold, were applied to the chest the patient sometimes stirred, in which case a wait of 1-2 minutes or a further $1 \mathrm{mg}$ of intravenous midazolam was given to reinstate the previous sleepy state. Patients were not sedated down to loss of eyelid reflexes.

With the external paddles pressed manually on to the gel pads below the right clavicle and the left lateral chest wall, an initial shock of $75 \mathrm{~J}$ was given (unless the patient had atrial flutter, when $50 \mathrm{~J}$ was used). When required, second and third shocks were given at $120 \mathrm{~J}$ and $200 \mathrm{~J}$. If the patient was of large build or obese, for the third shock large adhesive electrode pads from Zoll (Pro-Padz Biphasic Multifunction/ Pacing Electrodes) were used. These electrodes were positioned over the right anterior and left lateral chest. The manufacturers advise that these pads may be more successful than external paddles pressed on to gel pads, but they cost $£ 27.50$ a pair.

After cardioversion all patients received $200 \mu \mathrm{g}$ of flumazenil to reverse the midazolam. ${ }^{7}$ Usually the patient then returned to full wakefulness and was able to hold a conversation. The patient was then returned on the trolley to the main section of the day ward and a 12 lead ECG was recorded. The ECG was not monitored. About an hour later, the patient got up, dressed, and then sat out in the ward, but was not observed.

As there is some evidence that $\beta$ blockade may reduce recurrence of atrial fibrillation $(\mathrm{AF}),{ }^{8}$ if the patient was not taking a $\beta$ blocking drug, $25 \mathrm{mg}$ of atenolol twice daily was prescribed and digoxin was withdrawn. Warfarin was continued in all cases.

Before discharge, the chest wall was inspected and skin burns were graded as 0 , no erythema; 1 , mild erythema; 2 , moderate erythema; and 3, severe erythema with blister formation. The patients were asked if they remembered the

Abbreviations: AF, atrial fibrillation; AFFIRM, atrial fibrillation follow up investigation of rhythm management; INR, international normalised ratio; RACE, rate control versus electrical cardioversion for persistent atrial fibrillation 
Table 1 Patients' characteristics, history of atrial fibrillation, and medications

\begin{tabular}{|c|c|c|c|}
\hline & Group $1(n=368)$ & Group $2(n=210)$ & $\mathrm{p}$ Value \\
\hline Age (years) & $68(9.5)$ & $67.1(10.1)$ & \\
\hline Men/women & $69.3 \% / 30.7 \%$ & $75 \% / 25 \%$ & \\
\hline \multicolumn{4}{|l|}{ Rhythm } \\
\hline Atrial fibrillation & 365 & 208 & \\
\hline Atrial flutter & 3 & 2 & \\
\hline \multicolumn{4}{|l|}{ Cause of atrial fibrillation } \\
\hline Coronary artery disease & $55(14.9 \%)$ & $24(11.4 \%)$ & $0.25^{*}$ \\
\hline Hypertension & $163(44.2 \%)$ & $74(35.2 \%)$ & 0.041 \\
\hline Congestive cardiomyopathy & $25(6.8 \%)$ & $8(3.8 \%)$ & $0.144^{*}$ \\
\hline Valvar heart disease & $21(5.7 \%)$ & $22(10.5 \%)$ & 0.033 \\
\hline Post-cardiac surgery & $33(8.9 \%)$ & $20(9.5 \%)$ & $0.796^{*}$ \\
\hline Sick sinus syndrome & $7(1.9 \%)$ & $6(2.8 \%)$ & $0.446^{*}$ \\
\hline Idiopathic & $41(11.1 \%)$ & $22(10.5 \%)$ & $0.835^{*}$ \\
\hline Hyperthyroidism & $4(1.1 \%)$ & $1(0.5 \%)$ & $0.451^{*}$ \\
\hline ASD (after Amplatz closure) & $2(0.5 \%)$ & $2(1.0 \%)$ & $0.562^{*}$ \\
\hline Not recorded & $17(4.6 \%)$ & $31(14.8 \%)$ & \\
\hline \multicolumn{4}{|c|}{ Duration of atrial fibrillation (months) } \\
\hline $0-6$ & 112 (30.4\%) & $11(5.2 \%)$ & $<0.0001$ \\
\hline $6-12$ & $150(40.8 \%)$ & $36(17.1 \%)$ & $<0.0001$ \\
\hline$>12$ & $89(24.2 \%)$ & $136(64.8 \%)$ & $<0.0001$ \\
\hline Not known & $17(4.6 \%)$ & $27(12.9 \%)$ & $<0.0001$ \\
\hline \multicolumn{4}{|l|}{ Antiarrhythmic drugs } \\
\hline$\beta$ Blockers & $213(57.9 \%)$ & $96(45.7 \%)$ & 0.007 \\
\hline Amiodarone & $74(20.1 \%)$ & $18(8.6 \%)$ & $<0.0001$ \\
\hline Digoxin & 137 (37.2\%) & $67(31.9 \%)$ & $0.227^{*}$ \\
\hline Flecainide & $13(3.5 \%)$ & $10(4.8 \%)$ & $0.453^{*}$ \\
\hline Calcium antagonists & $98(26.6 \%)$ & $51(24.2 \%)$ & $0.578^{*}$ \\
\hline Propafenone & $1(0.3 \%)$ & 0 & \\
\hline Previous cardioversions & $27(7.33 \%)$ & $62(29.52 \%)$ & $<0.0001$ \\
\hline
\end{tabular}

shocks and if they had found the procedure unpleasant. Dates for follow up ECGs at one and four weeks were arranged.

The patients and results after one year of the new service (group 1) were compared with patients seen during the preceding year (group 2). In the previous service the procedure was performed by junior cardiologists with an anaesthetist specialist registrar. A short general anaesthetic was given with intravenous propofol or sevoflurane by inhalation. The patient was not routinely intubated. A monophasic defibrillator was used with electrode pads placed over the right anterior and the left lateral chest. The protocol of the energy of the shocks was $200 \mathrm{~J}, 200 \mathrm{~J}$, and then $360 \mathrm{~J}$. If the first two shocks were unsuccessful, the patient was usually turned over on to the right side and the next shock was given between the left anterior and left posterior chest wall. As mild to moderate chest wall erythema usually developed after cardioversion in group 2 patients, they were discharged with either hydrocortisone or silver sulfadiazine cream to apply for 2-5 days as necessary.

\section{RESULTS}

There were 368 patients in group 1 and 210 in group 2; table 1 shows their clinical details. More patients in group $2(29.5 \%)$ than group $1(7.4 \%)$ had a previous cardioversion $(\mathrm{p}<0.0001)$. More patients in group $\mathrm{l}(20.1 \%)$ than in group $2(8.6 \%)$ were receiving amiodarone $(p<0.0001)$.

\begin{tabular}{|ll|}
\hline $\begin{array}{l}\text { Table } 3 \text { Complications of cardioversion in group } 1 \\
\text { patients }\end{array}$ \\
\hline $\begin{array}{l}\text { Apnoea or respiratory problems } \\
\text { Skin erythema grade }\end{array}$ \\
0 & 0 \\
1 (mild) & $196(53 \%)$ \\
2 and 3 (moderate to severe) & $172(47 \%)$ \\
Shocks remembered & 0 \\
Shocks unpleasant & $38(10.3 \%)$ \\
Bradycardia requiring atropine & $13(3.5 \%)$ \\
Bradycardia requiring pacemaker & $14(3.8 \%)$ \\
& $2(0.5 \%)$ \\
\hline
\end{tabular}

Cardioversion was successful with $94.6 \%$ of patients in group 1 and $81.4 \%$ of patients in group $2(\mathrm{p}<0.0001)$ (table 2 ). The mean energy of shock needed for cardioversion was 117.5 (56.7) $\mathrm{J}$ for group $\mathrm{I}$ and 242.7 (72.7) $\mathrm{J}$ for group 2 $(\mathrm{p}<0.0001)$. Zoll Pro-Paz multifunctional/pacing electrode pads were used for 35 patients $(9.5 \%)$ in group 1 . The mean dose of midazolam for group 1 patients was 7.09 (4.76) $\mathrm{mg}$. Two patients were anaesthetised, as they had not become sedated despite $16 \mathrm{mg}$ and $12 \mathrm{mg}$ of midazolam. Complications were recorded prospectively for group 1 patients (table 3) but were not available from the retrospective audit of group 2 patients. No group 1 patients had

Table 2 Cardioversion process

\begin{tabular}{llll}
\hline & $\begin{array}{l}\text { Group 1 } \\
\text { (biphasic system) }\end{array}$ & $\begin{array}{l}\text { Group 2 } \\
\text { (monophasic system) }\end{array}$ & p Value \\
\hline Number of patients & 368 & 210 & \\
Successful cardioversions & $348(94.6 \%)$ & $171(81.4 \%)$ & $<0.0001$ \\
Mean energy of shock & $117.52(56.67)$ & $242.74(72.66)$ & $<0.0001$ \\
Mean number of shocks & $1.55(0.81)$ & $1.96(0.97)$ & \\
\hline
\end{tabular}


any episodes of apnoea or other respiratory complications. They had either no cutaneous reaction or only mild erythema of the chest wall (table 3). No hydrocortisone cream or silver sulfadiazine cream was needed. The shocks were remembered by $10.3 \%$ of patients and $3.5 \%$ considered them unpleasant.

In group 1,12 of 380 visits $(3.2 \%)$ were cancelled on the day of the procedure, as four patients were back in sinus rhythm; eight patients had a low INR and had been added to the list at short notice without being seen at the precardioversion clinic. In group 2, 65 of 275 (24\%) visits were cancelled on the day of the procedure (none of the patients in group 2 were seen in a pre-cardioversion clinic). The usual cause for cancellation was inadequate anticoagulant control detected by an INR checked on the morning of the procedure. The waiting time for cardioversion fell from 23 weeks to 12 weeks after the start of the new service, even though another hospital's list of patients for cardioversion had been taken over.

Of 295 patients from group 1 attending for a postcardioversion ECG, 65 patients $(22 \%)$ at one week and a further 52 patients at four weeks (for a total of 117 (39.6\%) were found to be back in AF.

\section{DISCUSSION}

We believe this paper reports the largest sample of patients who have received intravenous midazolam sedation for cardioversion, especially with the use of a biphasic defibrillator. There are concerns that midazolam may lead to respiratory depression down to an anaesthetic level needing the presence of an anaesthetist, ${ }^{9}$ but we have not found this. When midazolam was administered in a slow stepwise manner, oxygen saturations did not fall and usually a lower dose of midazolam was sufficient than when midazolam was given more rapidly. No patient required intubation or another form of respiratory support. The staff grade doctor and day care ward nurses were trained in airway management and resuscitation. Flumazenil was found to reverse promptly the sedative effect of midazolam and no side effects were encountered. ${ }^{7}$

Though the patients jump with the shock, only $10.3 \%$ remembered the shock(s) and only 3.5\% found them unpleasant. The lower energy (117.5 (56.7) J) and number of shocks (1.5 (0.8)) needed with the biphasic defibrillator reduced the pain and skin reactions. The high cardioversion success rate of $95 \%$ compared with the previous rate of $81 \%$ with the monophasic equipment has reduced referrals for internal cardioversion after failed cardioversion. However, this higher success rate among group 1 patients was in part due to a larger number receiving amiodarone and a shorter duration of AF than that among group 2 patients (table 1).

Attendance at the pre-cardioversion clinic greatly reduced cancellations on the day of the procedure (from $24 \%$ to $3.4 \%$ ), as problems with low INRs and return to sinus rhythm had already been detected and managed. The new service, with assessment both before and on the day of cardioversion, was more efficient and led to a reduced waiting time from 23 weeks to 12 weeks.

The RACE (rate control versus electrical cardioversion for persistent atrial fibrillation) ${ }^{10}$ and AFFIRM (atrial fibrillation follow up investigation of rhythm management) trials ${ }^{11}$ showed that, for many patients with $\mathrm{AF}$, rate control is sufficient and superior to rhythm control-that is, correction to sinus rhythm. This implies that, especially for asymptomatic and elderly patients where AF has been an incidental finding, cardioversion is not required. This view may change if new drug regimens are more successful in maintaining sinus rhythm. ${ }^{12}$ If a new antithrombin agent, such as ximelagatran, ${ }^{13}$ were successful in a fixed daily dose, the anticoagulant regimen before and after cardioversion would be greatly simplified. We have already noted in the second year of the new service a reduction of cardioversion referrals. For those who do require cardioversion, the regular use of intravenous midazolam with a biphasic defibrillator by a more experienced doctor offers a simple efficient procedure.

\section{Conclusions}

This study examined the efficacy and safety of a new service providing cardioversion with intravenous midazolam sedation and a biphasic defibrillator by an experienced senior doctor and assessment of patients in a pre-cardioversion clinic. The audit of the new service has found it to be safe, efficient, and an improvement on the previous service with a monophasic defibrillator and general anaesthesia.

We gratefully acknowledge the active participation in the new cardioversion service of Diane Curtis, Annie Daly, Shirley Henderson, Bavisha Pattani, Rosemary Shelton, and Paul Stafford.

\section{Authors' affiliations}

P J B Hubner, S Gupta, I McClellan, Departments of Cardiology and Anaesthetics, Glenfield Hospital, University Hospitals of Leicester NHS Trust, Groby Road, Leicester LE3 9QP, UK

\section{REFERENCES}

1 Raipancholia R, Sentinella, Lynch L. Role of conscious sedation for external cardioversion. Heart 2001;86:571-2.

2 Pugh PJ, Spurrell P, Kamalvand K, et al. Sedation by physician with diazepam for DC cardioversion of atrial arrhythmias. Heart 2001;86:572-3.

3 Goldener BG, Baker J, Accordino A, et al. Electrical cardioversion of atrial fibrillation or flutter with conscious sedation in the age of cost containment. Am Heart J 1998;136:961-4.

4 Mittal S, Ayati S, Stein KM, et al. Transthoracic cardioversion of atrial fibrillation: comparison of rectilinear biphasic versus damped sine wave monophasic shocks. Circulation 2000;101:1282-7.

5 Scholten M, Szili-Torok T, Klootwijk P, et al. Comparison of monophasic and biphasic shocks for transthoracic cardioversion of atrial fibrillation. Heart 2003;89:1032-4.

6 UK Academy of Medical Royal Colleges and their Faculties. Implementing and ensuring safe sedation for healthcare procedures in adults. Nov 2001. Report of Intercollegiate Working Party chaired by the Royal College of Anaesthetists. www.rcoa.ac.uk/docs/safesedationpractice.pdf.

7 Fennelly ME, Powell H, Galletly DC, et al. Midazolam sedation reversed with flumazenil for cardioversion. Br J Anaesth 1992;68:303-5.

8 Juul-Moller S, Edvardsson N, Rehnqvist-Ahlberg N. Sotalol versus quinidine for the maintenance of sinus rhythm after direct current conversion of atrial fibrillation. Circulation 1990;82:1932-9.

9 Harrison SJ, Mayet J. Physician administered sedation for DC cardioversion. Heart 2002;88:117-8.

10 Van Gelder IC, Hagens VE, Bosker HA. Rate control versus electrical cardioversion for persistent atrial fibrillation (RACE) study group. N Engl J Med 2002;347: 1834-40.

11 Wyse DG, Waldo AL, DiMarco JP, et al. The atrial fibrillation follow-up investigation of rhythm management (AFFIRM) investigators. A comparison of rate control and rhythm control on patients with atrial fibrillation. N Engl J Med 2002;347:1825-33.

12 Ueng K-C, Tsai T-P, Yu W-C, et al. Use of enalapril to facilitate sinus rhythm maintenance after external cardioversion of long-standing persistent atrial fibrillation. Eur Heart J 2003;24:2090-8.

13 Petersen P, Grind M, Adler J for the SPORTIF II Investigators. Ximelagatran versus warfarin for stroke prevention in patients with nonvalvular atrial fibrillation. J Am Coll Cardiol 2003;41:1445-51. 